\title{
Study on Shale Adsorption Equation Based on Monolayer Adsorption, Multilayer Adsorption, and Capillary Condensation
}

\author{
Qing Chen, ${ }^{1,2}$ Yuanyuan Tian, ${ }^{1,2}$ Peng Li, ${ }^{2}$ Changhui Yan, ${ }^{1,2}$ Yu Pang, ${ }^{3}$ Li Zheng, \\ Hucheng Deng, ${ }^{2}$ Wen Zhou, ${ }^{1}$ and Xianghao Meng ${ }^{1}$ \\ ${ }^{1}$ State Key Laboratory of Oil and Gas Reservoir Geology and Exploration, Chengdu University of Technology, Chengdu 610059, China \\ ${ }^{2}$ College of Energy Resource, Chengdu University of Technology, Chengdu 610059, China \\ ${ }^{3}$ Petroleum Engineering, Texas Tech University, Lubbock, TX, USA \\ Correspondence should be addressed to Yuanyuan Tian; yuanyuan-tian@outlook.com
}

Received 12 February 2017; Revised 14 August 2017; Accepted 11 September 2017; Published 18 October 2017

Academic Editor: Davide Vione

Copyright (C) 2017 Qing Chen et al. This is an open access article distributed under the Creative Commons Attribution License, which permits unrestricted use, distribution, and reproduction in any medium, provided the original work is properly cited.

\begin{abstract}
Shale gas is an effective gas resource all over the world. The evaluation of pore structure plays a critical role in exploring shale gas efficiently. Nitrogen adsorption experiment is one of the significant approaches to analyze pore size structure of shale. Shale is extremely heterogeneous due to component diversity and structure complexity. Therefore, adsorption isotherms for homogeneous adsorbents and empirical isotherms may not apply to shale. The shape of adsorption-desorption curve indicates that nitrogen adsorption on shale includes monolayer adsorption, multilayer adsorption, and capillary condensation. Usually, Langmuir isotherm is a monolayer adsorption model for ideal interfaces; BET (Brunauer, Emmett, Teller) adsorption isotherm is a multilayer adsorption model based on specific assumptions; Freundlich isotherm is an empirical equation widely applied in liquid phase adsorption. In this study, a new nitrogen adsorption isotherm is applied to simultaneously depict monolayer adsorption, multilayer adsorption, and capillary condensation, which provides more real and accurate representation of nitrogen adsorption on shale. In addition, parameters are discussed in relation to heat of adsorption which is relevant to the shape of the adsorption isotherm curve. The curve fitting results indicate that our new nitrogen adsorption isotherm can appropriately describe the whole process of nitrogen adsorption on shale.
\end{abstract}

\section{Introduction}

Shale gas has attracted much attention in United States, China, Canada, and so forth, because of the gas storage mechanism and recovery potential of shale gas reservoirs $[1$, 2]. To investigate gas adsorption capacity and pore size distribution of shale rocks, high-pressure methane adsorption and low-pressure nitrogen or carbon dioxide adsorption experiments are conducted, respectively. Many researches have been done to find and modify adsorption equations suitable for describing methane adsorption. Considering methane adsorption as monolayer adsorption, Langmuir equation, L-F (Langmuir-Freundlich) equation, and M-L (modified Langmuir) equation are successfully applied to evaluate methane adsorption [3-5]. Furthermore, D-R (DubininRadushkevich) equation, D-A (Dubinin-Astakhov) equation, and S-D-R (supercritical Dubinin-Radushkevich) equation are also used with consideration of methane adsorption as micropore filling [6-8]. For carbon dioxide adsorption, to take into account the monolayer adsorption property, both Langmuir equation and L-F equation are applied to depict variations of the adsorption capacity with pressure [9-11]. On the contrary, it is hard to find an equation to depict low-pressure nitrogen adsorption because of the complicated adsorption mechanism. On the basis of BDDT (BrunauerDeming-Deming-Teller) adsorption isotherm classification, nitrogen adsorption belongs to type IV, which indicates that it includes three processes: monolayer adsorption, multilayer adsorption, and capillary condensation. Unfortunately, the majority of adsorption equations are developed based on only one kind of adsorption mechanism, and they can be categorized into three aspects: monolayer adsorption, multilayer adsorption, and micropore filling.

In terms of monolayer adsorption, a widely accepted one is Langmuir adsorption equation which assumed only one type of adsorption sites on the surface of adsorbent $[12,13]$. 
When extending the Langmuir equation for gas-liquid-phase adsorption studies, two types of sites are considered and the relationship between equilibrium concentration and amount of adsorbate is obtained [14-19]. Because the Langmuir equation describes adsorption on homogeneous surface, Gaussian energy distribution is used to adjust monolayer adsorption theory to heterogeneous surface [20-22]. To study multicomponent, monolayer adsorption of multicomponent gas, the assumption that the saturated amount of adsorption for each component is equal based on Langmuir equation was derived $[23,24]$.

In the aspect of multilayer adsorption, BET (Brunauer, Emmett, and Teller) equation is the most popular one, and it proposes a multilayer adsorption model which assumes that the interaction on adsorbent surface is much larger than that between neighboring adsorbate molecules [25-27]. The theory is appropriate for adsorption on solid surfaces with homogeneous chemical properties, which is frequently applied to calculate specific surface area for porous media. To extend BET equation to multicomponent adsorption, three kinds of n-component BET equations were proposed considering that adsorbed layers have evaporation-condensation characters for liquid mixture, supposing that the adsorbed layer of gas mixture is an ideal solution according to statistic thermodynamics and assuming gas mixture is immiscible liquid [28-31].

Micropore filling is also a common adsorption mechanism, which is introduced on the basis of Polanyi adsorption potential theory [32]. According to thermodynamics, adsorption potential $(\varepsilon)$ is transferring unit mass of adsorbate from gas phase to adsorbent surface. On account of thermodynamics, D-R and D-A equations were generated [33-36]. Changing micropore filling to surface coverage and keeping feature of Gaussian distribution of energy, D-RK (Dubinin-Radushkevich-Kaganer) equation was built [37, 38]. For micropore filling on nonregular porous media, D$\mathrm{R}$ equation was modified by fractal dimension function [39]. Furthermore, for supercritical fluid adsorption, S-D-R equation was built [7].

In fact, most adsorbents are heterogeneous porous media. Combination of adsorption equations is a solution to build equation for heterogeneous adsorbent. In studies of methane adsorption, empirical Freundlich equation was combined with Langmuir equation to obtain the L-F equation which is widely used in depicting CBM (coal bed methane) adsorption successfully $[40,41]$. Moreover, heterogeneity of adsorbent surface has been taken into account, and an adsorption equation was built to express the relationship between equilibrium concentration and mass of adsorbate by combining Freundlich adsorption isotherm with Langmuir adsorption isotherm $[42,43]$.

It is clear that these adsorption equations only focus on one adsorption mechanism and cannot be applied to interpret monolayer adsorption, multilayer adsorption, and capillary condensation simultaneously. In addition, it is well known that shale consists of clay minerals (kaolinite, illite, chlorite, etc.), detrital minerals (quartz, feldspar, etc.), and some characteristic minerals (such as pyrite) [44-48], each with its specific adsorption property. On the other hand, pore size distribution in shale is irregular [49], which results in an uneven distribution of adsorption potential. Compared with homogeneous materials used in other interfacial phenomenon studies, shale is an extremely heterogeneous adsorbent. However, most of current adsorption models assume that adsorbent is homogenous. Hence, our research is aiming at building a new adsorption equation for shale which enables us to depict complex adsorption including monolayer adsorption, multilayer adsorption, and capillary condensation.

\section{Experiment}

Adsorption and desorption data of shale measured by nitrogen at low temperature $(77 \mathrm{~K})$ is a fundamental method to analyze pore structure of shale. Samples were collected from Yanchang formation (Triassic, Ordos), Pingliang formation (Ordovician, Ordos), Wulalik formation (Ordovician, Ordos), Xujiahe formation (Triassic, Sichuan), Niutitang formation (Cambrian, Sichuan), and Doushantuo formation (Ediacaran, Sichuan). Properties of samples are described in Table 1. All samples were ground to pass a sieve size of 60 mesh $(250 \mu \mathrm{m})$. For outgassing, the pulverized samples were dried and vacuumized at $80^{\circ} \mathrm{C}$ for 12 hours.

The apparatus used for nitrogen adsorption experiment is Quadrasorb SI surface area and pore size analyzer (manufactured by Quantachrome in USA) which is provided by State Key Laboratory of Oil \& Gas Reservoir Geology and Exploitation (China). There are four stations of the experimental instrument. The lower limitation of specific surface area is $0.01 \mathrm{~m}^{2} / \mathrm{g}$ for nitrogen. In the aspect of pore size distribution analysis, the minimum pore volume is $0.0001 \mathrm{cc} / \mathrm{g}$ (STP), and the pore size range is $0.35 \sim 400 \mathrm{~nm}$. In our experiment, nitrogen is used as adsorbate. Measurement is conducted at temperature $77 \mathrm{~K}$, and the minimum $P / P_{0}$ is 0.001 .

All the experimental data are prepared to analyze nitrogen adsorption processes and determine the value of parameters in shale adsorption isotherm.

\section{Adsorption Characteristics of Nitrogen Adsorbed on Shale}

3.1. Adsorption Processes. According to BDDT (BrunauerDeming-Deming-Teller) adsorption isotherm classification [50], nitrogen adsorption isotherms of shale belong to type IV (Figure 1), which indicates that adsorption on shale can be divided into three stages: monolayer adsorption, multilayer adsorption, and capillary condensation [51-54]. The three stages can be specifically expressed as follows: most adsorption isotherms of shale have an inflection point at low relative pressure, which refers to saturated adsorbed content in monolayer adsorption regime. Before this point, only monolayer adsorption takes place. As relative pressure increases, the thickness of adsorbed layers gradually increases and multilayer adsorption occurs. When relative pressure reaches initial capillary condensation pressure (usually around 0.4 $P / P_{\mathrm{o}}$ ), adsorption-desorption curve forms hysteresis loop, 
TABLE 1: Curve fitting parameters of shale adsorption isotherm for 80 samples.

\begin{tabular}{|c|c|c|c|c|c|c|}
\hline Number & $A$ & $B$ & $K$ & $M$ & $N$ & $R$-Square \\
\hline D1 & 0.0537 & 1.9980 & 2132.0000 & 1.4890 & 0.0993 & 0.9988 \\
\hline D2 & 6.9810 & 0.0150 & 203.5000 & 0.9568 & 203.3000 & 0.9129 \\
\hline D3 & 0.0780 & 2.3980 & 0.0000 & 0.9168 & 3.8730 & 0.7652 \\
\hline $\mathrm{D} 4$ & 2.0550 & 1.2430 & 3.7850 & 0.5093 & 5274.0000 & 0.9991 \\
\hline D5 & 2.3920 & 0.2903 & 783.3000 & 0.7181 & 538.0000 & 0.8952 \\
\hline D6 & 5.2550 & 1.5350 & 6.2590 & 0.1476 & 191.1000 & 0.9983 \\
\hline D7 & 1.6750 & 1.1630 & 3.2210 & 0.2803 & 144.5000 & 0.9999 \\
\hline D8 & 1.9080 & 1.5610 & 4.1690 & 0.3121 & 1422.0000 & 0.9994 \\
\hline D9 & 2.2440 & 1.3200 & 6.7910 & 0.2632 & 232.6000 & 0.9993 \\
\hline D10 & 1.6210 & 1.2640 & 5.0760 & 0.4035 & 2745.0000 & 0.9980 \\
\hline D11 & 0.9914 & 1.1540 & 5.6780 & 0.4159 & 6902.0000 & 0.9993 \\
\hline D12 & 5.4060 & 1.7330 & 191.1000 & 0.4047 & 201.7000 & 0.9003 \\
\hline D13 & 5.3580 & 0.3832 & 208.0000 & 0.4707 & 202.8000 & 0.8984 \\
\hline D14 & 4.2840 & 1.4770 & 1896.0000 & 0.2662 & 5.7960 & 0.9995 \\
\hline D15 & 8.5540 & 1.3940 & 59.1100 & 0.5487 & 7595.0000 & 0.9079 \\
\hline D16 & 3.0770 & 1.5530 & 2.5480 & 0.2783 & 817.0000 & 0.9995 \\
\hline D17 & 7.4640 & 0.1425 & 650.6000 & 0.6635 & 333.4000 & 0.9124 \\
\hline D18 & 3.4710 & 1.5220 & 6.1130 & 0.2741 & 427.4000 & 0.9995 \\
\hline D19 & 3.3230 & 0.0003 & 427.4000 & 0.5498 & 423.1000 & 0.9088 \\
\hline D20 & 3.9300 & 0.0836 & 561.5000 & 0.4809 & 334.3000 & 0.9303 \\
\hline D21 & 3.5090 & 1.4470 & 5.5610 & 0.2747 & 723.2000 & 0.9991 \\
\hline D22 & 1.3000 & 1.4950 & 292.4000 & 0.4657 & 4.5470 & 0.9998 \\
\hline D23 & 4.2450 & 1.4390 & 3.9790 & 0.2875 & 408.9000 & 0.9985 \\
\hline D24 & 2.8740 & 1.0500 & 53.0000 & 0.4740 & 53.6000 & 0.9213 \\
\hline D25 & 2.9540 & 0.4405 & 701.8000 & 0.4577 & 275.8000 & 0.9257 \\
\hline D26 & 3.5920 & 0.2153 & 209.1000 & 0.3085 & 208.2000 & 0.9436 \\
\hline D27 & 5.3050 & 1.5090 & 5.4720 & 0.2243 & 268.2000 & 0.9981 \\
\hline D28 & 5.1140 & 1.4920 & 4.6400 & 0.2279 & 346.7000 & 0.9986 \\
\hline D29 & 9.0830 & 1.5220 & 242.3000 & 0.1936 & 2.4390 & 0.9994 \\
\hline D30 & 7.0750 & 1.4830 & 6.5960 & 0.2288 & 2220.0000 & 0.9957 \\
\hline D31 & 2.7600 & 1.3680 & 6.0210 & 0.2718 & 156.4000 & 0.9990 \\
\hline D32 & 6.3140 & 1.4600 & 5.4280 & 0.2655 & 6569.0000 & 0.9966 \\
\hline D33 & 6.6460 & 1.5110 & 4.5510 & 0.2274 & 7304.0000 & 0.9943 \\
\hline D34 & 4.9060 & 1.9610 & 162.9000 & 0.5029 & 206.6000 & 0.9260 \\
\hline D35 & 6.0750 & 1.5820 & 4.5020 & 0.2520 & 642.7000 & 0.9998 \\
\hline D36 & 10.4800 & 1.5260 & 5.6510 & 0.2440 & 216.6000 & 0.9985 \\
\hline D37 & 5.4940 & 1.4900 & 6.4730 & 0.2477 & 194.1000 & 0.9984 \\
\hline D38 & 5.4510 & 1.5800 & 4.8690 & 0.2569 & 1299.0000 & 0.9991 \\
\hline D39 & 9.2010 & 1.5080 & 5.0390 & 0.2308 & 174.4000 & 0.9987 \\
\hline D40 & 3.6820 & 1.3920 & 3.6970 & 0.3226 & 2108.0000 & 0.9997 \\
\hline D41 & 0.2399 & 1.3620 & 7.7860 & 0.5925 & 153.7000 & 0.9969 \\
\hline D42 & 4.5800 & 1.5770 & 4.8860 & 0.3121 & 1525.0000 & 0.9991 \\
\hline D43 & 4.6990 & 1.3130 & 3.8670 & 0.3180 & 1697.0000 & 0.9993 \\
\hline D44 & 0.8405 & 1.7690 & 404.3000 & 0.3685 & 3.9270 & 0.9997 \\
\hline D45 & 0.5450 & 1.3380 & 15.3900 & 1.2740 & 2570.0000 & 0.9852 \\
\hline D46 & 1.6880 & 0.6039 & 176.0000 & 1.1490 & 0.0014 & 0.9834 \\
\hline D47 & 1.9000 & 0.5685 & 206.7000 & 1.3950 & 203.6000 & 0.9780 \\
\hline D48 & 3.2030 & 1.5100 & 3.9550 & 0.5210 & 1347.0000 & 0.9994 \\
\hline D49 & 0.1630 & 1.1610 & 3.9160 & 0.5117 & 124.4000 & 0.9996 \\
\hline D50 & 0.3986 & 1.2930 & 42.2300 & 1.7860 & 63.0900 & 0.9736 \\
\hline D51 & 3.0890 & 1.4760 & 5.7340 & 0.3389 & 897.6000 & 0.9988 \\
\hline D52 & 2.4900 & 1.3240 & 3.8420 & 0.4336 & 872.2000 & 0.9989 \\
\hline
\end{tabular}


TABle 1: Continued.

\begin{tabular}{|c|c|c|c|c|c|c|}
\hline Number & $A$ & $B$ & K & $M$ & $N$ & $R$-Square \\
\hline D53 & 3.1810 & 0.1210 & 556.3000 & 1.0080 & 276.6000 & 0.9509 \\
\hline D54 & 2.0150 & 1.4120 & 4973.0000 & 0.5012 & 4.8210 & 0.9991 \\
\hline D55 & 5.4370 & 1.4850 & 5.6280 & 0.2821 & 1196.0000 & 0.9994 \\
\hline D56 & 4.9370 & 1.5060 & 5.7860 & 0.3235 & 633.8000 & 0.9993 \\
\hline D57 & 1.1190 & 1.5900 & 2357.0000 & 0.8201 & 6.8430 & 0.9994 \\
\hline D58 & 2.5580 & 1.4510 & 3.8680 & 0.3408 & 690.5000 & 0.9988 \\
\hline D59 & 2.5710 & 1.3870 & 4.9770 & 0.4927 & 357.1000 & 0.9995 \\
\hline D60 & 0.7093 & 1.3030 & 3.2820 & 0.6943 & 282.8000 & 0.9996 \\
\hline D61 & 0.5753 & 1.5290 & 700.2000 & 0.4714 & 3.8960 & 0.9999 \\
\hline D62 & 0.2555 & 0.2743 & 32.7500 & 3.2820 & 0.1412 & 0.9609 \\
\hline D63 & 4.1530 & 1.4710 & 4.0830 & 0.3707 & 229.8000 & 0.9988 \\
\hline D64 & 0.3084 & 1.2180 & 3.3540 & 0.5845 & 172.4000 & 0.9989 \\
\hline D65 & 0.1870 & 0.5533 & 41.5700 & 1.5160 & 0.0292 & 0.9894 \\
\hline D66 & 0.1506 & 1.2430 & 1.9260 & 0.6289 & 102.3000 & 0.9997 \\
\hline D67 & 0.1322 & 1.1130 & 3.5120 & 0.4219 & 101.8000 & 0.9998 \\
\hline D68 & 1.8820 & 1.3280 & 4.1040 & 0.3971 & 193.7000 & 0.9989 \\
\hline D69 & 1.1050 & 1.2280 & 3.9960 & 0.4548 & 146.3000 & 0.9995 \\
\hline D70 & 3.5390 & 1.3730 & 297.5000 & 1.1020 & 389.5000 & 0.9095 \\
\hline D71 & 0.2066 & 1.8990 & 597.9000 & 0.5551 & 4.6210 & 0.9999 \\
\hline D72 & 1.7930 & 1.3680 & 5.0270 & 0.5813 & 291.4000 & 0.9997 \\
\hline D73 & 3.0830 & 1.4350 & 5.1210 & 0.5572 & 435.3000 & 0.9996 \\
\hline D74 & 1.5910 & 1.3670 & 7.1400 & 0.5368 & 11840.0000 & 0.9981 \\
\hline D75 & 2.7250 & 2.5950 & 159.2000 & 0.9335 & 174.9000 & 0.9170 \\
\hline D76 & 0.7462 & 0.1465 & 84.1800 & 2.1390 & 0.0039 & 0.9910 \\
\hline D77 & 3.8900 & 0.1753 & 500.5000 & 0.7077 & 264.5000 & 0.9242 \\
\hline D78 & 0.1222 & 1.9200 & 1187.0000 & 0.4956 & 7.9260 & 0.9999 \\
\hline D79 & 0.1362 & 1.8620 & 126.3000 & 0.4758 & 3.7370 & 0.9998 \\
\hline D80 & 0.1082 & 1.8330 & 96.1900 & 0.4922 & 2.8620 & 0.9996 \\
\hline
\end{tabular}

which demonstrates that capillary condensation exists in the process of nitrogen adsorbed on shale.

3.2. Adsorption Equations and Adsorption Processes. As mentioned above, shale adsorption includes processes of monolayer adsorption, multilayer adsorption, and capillary condensation. Therefore, the generated new shale adsorption isotherm would be capable of depicting all features of these processes.

In terms of monolayer adsorption, Langmuir equation will be an appropriate choice. Langmuir built an adsorption model with the following assumptions: (1) surface of adsorbent has one type of adsorption sites and one site can accommodate only one adsorbate molecule or atom; (2) the surface is homogeneous and there is no lateral interaction between adsorbate molecules; (3) adsorption reaches dynamic equilibrium [55]. Based on these assumptions, the adsorption isotherm can be given as

$$
V=\frac{V_{m} b P}{1+b P}
$$

All terms used in the equations are defined in the nomenclature section.
For multilayer adsorption, BET adsorption isotherm is a representation of multilayer adsorption model generated by Brunauer, Emmett, and Teller, which assumes the interaction between adsorbate and adsorbent surface is much larger than that between neighboring molecules. The theory is appropriate for adsorption on surface of solid with homogeneous chemical properties, which is frequently applied to calculate specific surface area for porous media. The BET equation can be expressed as [25]

$$
V=\frac{V_{m} c P}{\left(P_{0}-P\right)\left[1+(c-1)\left(P / P_{0}\right)\right]} .
$$

Capillary condensation is a process where gas phase transforms into liquid phase. Thus, an adsorption equation applicable to describe liquid adsorption is suitable for this adsorption stage. Among investigated adsorption equations, Freundlich adsorption isotherm is an empirical equation describing equilibrium concentration of solute in solution with respect to concentration of solute adsorbed on the surface of solvent. The adsorption equation is [56]

$$
m=k P^{1 / n} \text {. }
$$

Figure 2 points out that if we only apply Langmuir isotherm to shale adsorption in low relative pressure section 

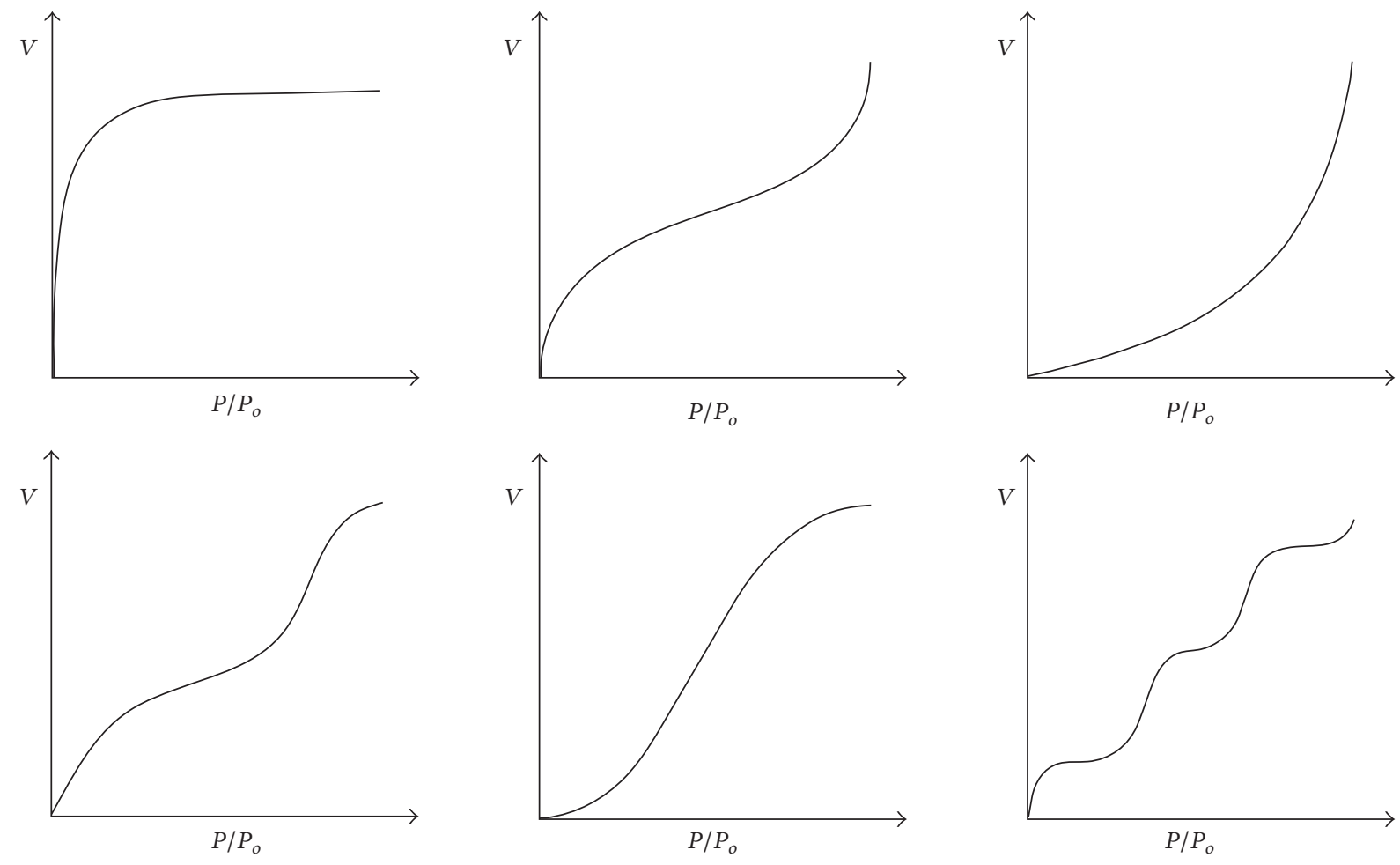

Figure 1: Classification of BDDT adsorption isotherms (from Brunauer, Sing et al., 1940).

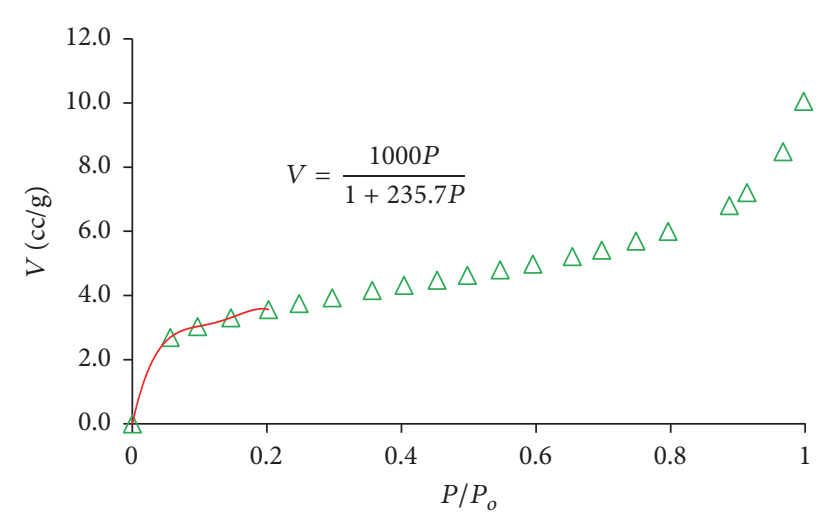

$$
\begin{array}{ll}
\triangle & \text { D47 } \\
- & \text { Langmuir }
\end{array}
$$

FIGURE 2: Application of Langmuir isotherm to nitrogen adsorption isotherm for shale at low relative pressure section.

(before the inflection point where monolayer adsorption switches to multilayer adsorption), Langmuir isotherm can properly match experimental data, which indicates that Langmuir isotherm is suitable for monolayer adsorption in shale and then justifies the analytical result that monolayer adsorption takes place in the process of nitrogen adsorption at low temperature for shale.

As a normal method to acquire surface area of shale, multipoint BET method testifies that BET equation can be applied to describe adsorption on shale at certain conditions (usually relative pressure below $0.4 P / P_{0}$ ). From curve

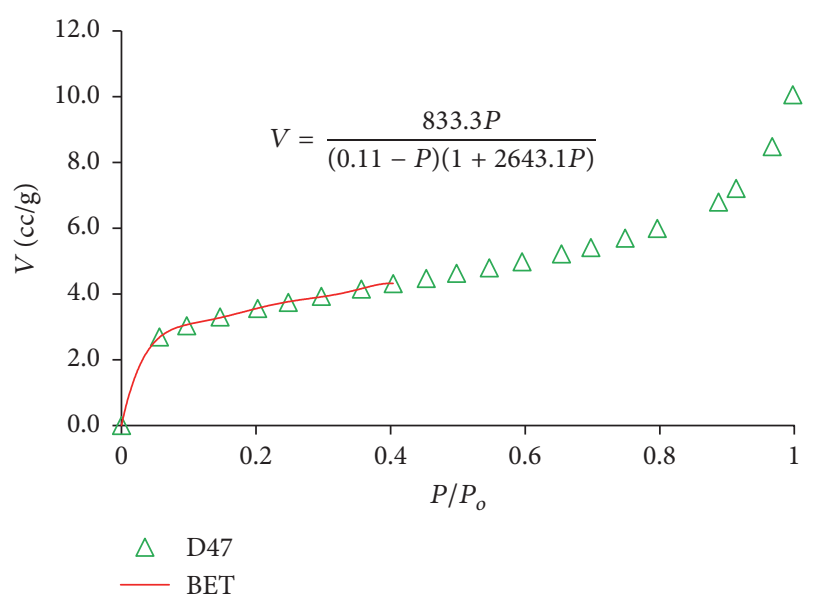

FIGURE 3: Application of BET isotherm to nitrogen adsorption isotherm for shale before capillary condensation.

fitting result (Figure 3), BET is appropriate for low and medium relative pressure sections, which illustrates that BET adsorption isotherm can depict experimental data before the presence of capillary condensation. This also reveals that multilayer adsorption exists in the process of nitrogen adsorption isotherm for shale.

As shown in Figure 4, Freundlich isotherm fits the medium-high relative pressure section of nitrogen adsorption on shale, especially relative pressure section after occurrence of capillary condensation. 


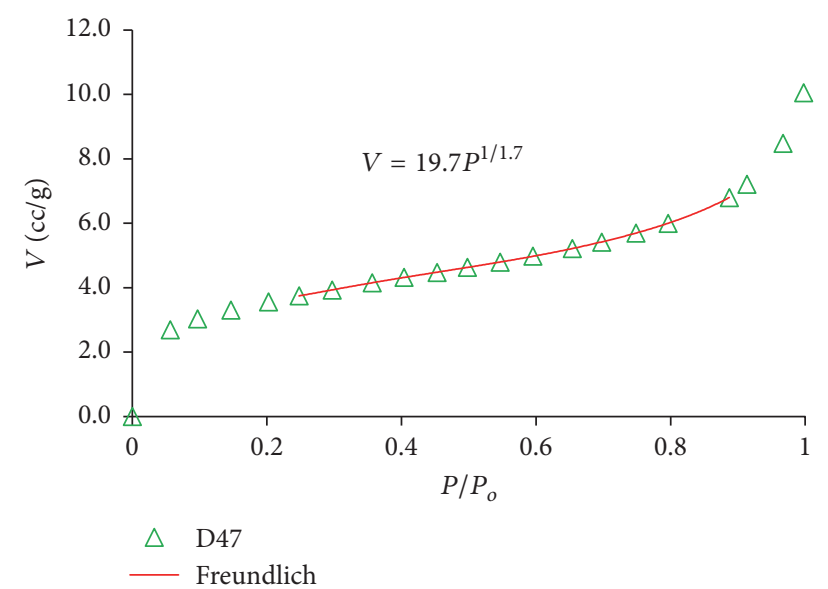

Figure 4: Application of Freundlich isotherm to liquefied nitrogen adsorption isotherm for shale for medium-high relative pressure section.

On behalf of potentials of the three equations representing adsorption in different relative pressure sections, the new adsorption equation for shale needs to contain features of Langmuir isotherm, BET isotherm, and Freundlich isotherm.

\section{Result}

BET and Freundlich adsorption isotherms can be changed to functions which consider relative pressure as an independent variable. Thereafter, Langmuir adsorption isotherm is a case of BET adsorption isotherm, in which the pressure is much lower than saturated vapor pressure.

Rearranging BET adsorption isotherm equation one gets

$$
V=\frac{V_{m} c P_{r}}{-(c-1) P_{r}^{2}+(c-2) P_{r}+1} .
$$

Substituting $P_{r}$ into (3) gives

$$
m=k P_{r}^{1 / n} P_{0}^{1 / n} .
$$

Freundlich adsorption isotherm describes the relationship between pressure and mass of adsorbate adsorbed on surface of adsorbent per unit of mass. In order to express adsorption capacity in same dimension, (5) is converted to

$$
V=\frac{k P_{r}^{1 / n} P_{0}^{1 / n}}{\rho g} .
$$

Under experimental conditions, saturated vapor pressure and density of adsorbate are constants. Therefore, setting $k P_{0}^{1 / n} / \rho g=k^{\prime}$, then (6) becomes

$$
V=k^{\prime} P_{r}^{1 / n}
$$

From (1) and (2), the coefficient and exponent of pressure in Langmuir and BET adsorption isotherm $\left(V_{m}, b, c\right)$ correspond to physical and chemical parameters of monolayer and multilayer adsorption. We apply the function with a form of BET adsorption isotherm and combine Freundlich adsorption isotherm which can describe characteristic of liquid adsorption to build up shale adsorption isotherm. The coefficient and exponent of relative pressure are variable fitting parameters in the new shale adsorption isotherm expressed as follows:

$$
V=\frac{A P_{r}^{M}}{(1-B) P_{r}^{N}+(B-2) P_{r}^{K}+1} .
$$

$A, B$ are undetermined coefficients; $M, N, K$ are undetermined exponent.

\section{Discussion}

5.1. Physical and Chemical Meaning of Variables in Shale Adsorption Isotherm Equation. From above discussion, coefficient and exponent in the new shale adsorption isotherm equation are related to physical and chemical meanings of coefficients and exponents of Langmuir, BET, and Freundlich adsorption isotherms.

Variable $A$ in (8) can be given as

$$
A=V_{m} c P_{0}^{M} .
$$

Thus, $A$ is related to maximum amount of monolayer adsorption $\left(V_{m}\right)$, adsorption heat according to formula of $c$ which will be detailed below, saturated vapor pressure at experimental temperature $\left(P_{0}\right)$, and exponent $M$.

Variable $B$ in (8) is

$$
B=c
$$

Since the physical and chemical meaning of variable $B$ in adsorption isotherm equals coefficient $c$ in BET isotherm [57], $c$ is expressed as follows based on BET theoretical derivation [58]:

$$
c=\frac{a_{1} g e^{\left(\left(E_{1}-E_{L}\right) / R T\right)}}{b_{1}} .
$$

$B$ is related to heat of adsorption $\left(E_{1}, E_{L}\right)$ and experimental temperature $(T)$.

Thermodynamically, the expression of exponent $n$ in Freundlich adsorption isotherm is $[59,60]$

$$
n=-\frac{\Delta H_{m}}{R T}
$$

Compared with exponents of relative pressure in (8), coefficients $M, N$, and $K$ are relevant to experimental temperature, which indicates that the enthalpy $\Delta H_{m}$ represents the strength of adsorption effect.

After clarifying the physical and chemical meaning of variables in (8), the range of these variables should be determined.

In (9), $V_{m}, c, P_{0}^{M}$ are all positives, and then $A$ should be positive $(A>0)$.

In BET theory, it is assumed that the strength of interaction between adsorbate at first adsorbed layer and adsorbent 
is much bigger than the strength between adsorbates at subsequent layers. Thus, set heat of adsorption between subsequent adsorbates as $E_{L}$. Then, $E_{1}$ represents the heat of adsorption between adsorbate at first layer and adsorbent, and $E_{1}>E_{L}$. Thus, $c$ must be larger than 0 , and then we can obtain $B>0$.

In terms of adsorption isotherm system:

$$
\Delta H_{m}=H_{2}-H_{1}=\left(U_{2}+P_{2} V_{2}\right)-\left(U_{1}+P_{1} V_{1}\right) \text {. }
$$

At given temperature, based on ideal gas law, $P_{1} V_{1}=$ $P_{2} V_{2}$ can be obtained. Thus, in the whole system, change in adsorption enthalpy is equal to change in internal energy; namely, $\Delta H_{m}=\Delta U$. The adsorption is a process of heat release, $\Delta U<0$, so $\Delta H_{m}<0$ and all variables $M, N, K$ are positive.

For each shale sample, these parameters can be calculated by the new shale adsorption isotherm based on experimental data.

5.2. Specialization of Shale Adsorption Isotherm. When $M=$ $N=1 ; A=V_{m} b ; B=b,(8)$ can be simplified to (1) which is Langmuir adsorption isotherm.

When $M=K=1 ; N=2$, (8) can be simplified to

$$
V=\frac{A P_{r}}{(1-B) P_{r}^{2}+(B-2) P_{r}+1} .
$$

At the right hand side of equation, multiply both numerator and denominator by saturated vapor pressure $P_{0}$ as

$$
V=\frac{A P}{(1-B) P_{r}^{2} P_{0}+(B-2) P_{r} P_{0}+P_{0}} .
$$

The term $(B-2) P_{r} P_{0}$ can be written as $(B-1) P_{r} P_{0}-P_{r} P_{0}$. Equation (15) can be converted to

$$
V=\frac{A P}{\left(P_{0}-P\right)\left[1+(B-1)\left(P / P_{0}\right)\right]} .
$$

Then, $A=V_{m} * c ; B=c$, and (16) converts to BET adsorption isotherm as (2). (7).

In (8), if $M \gg 1 ; K \gg 1, A=k^{\prime} P_{0}^{M}, M=1 / n$, reduces to

By multiplying density of adsorbate $(\rho)$ on both sides of (7) one gets

$$
m=k^{\prime} P^{1 / n} \rho
$$

Setting $k^{\prime} \rho=k$, then (17) can be simplified to Freundlich adsorption isotherm as (3).

5.3. Application of New Adsorption Equation. According to the new shale adsorption isotherm equation and the range of variables, we applied Matlab to perform curve fitting of relative pressure versus amount of adsorption for 80 shale samples. The results of 6 samples are selected randomly and displayed in Figure 5, and the other fitting results are shown in Table 1. It appears that average value of $R^{2}$ is 0.9782 , maximum value of $R^{2}$ is 0.9999 , minimum value of $R^{2}$ is 0.7652 , and the percentage of shale samples for which the value of $R^{2}$ is larger than 0.9 is $96.25 \%$. It indicates that the new generated shale adsorption isotherm can represent a complete process of adsorption including monolayer adsorption, multilayer adsorption, and capillary condensation processes compared with Langmuir, BET, and Freundlich adsorption isotherms individually. In particular, it demonstrates better performance on depicting nitrogen adsorption isotherm at low temperature.

5.4. Coefficient B and the Shape of Adsorption Curve. Taking into account the physical and chemical meaning of coefficient $B$ in the new generated shale adsorption isotherm, it represents coefficient $c$ in BET isotherm (11). According to the research by Kondou et al. [61], the value of $c$ in BET isotherm is related to heat of adsorption. The value of $c$ is bigger, and the heat of adsorption is larger, which indicates that strength of interaction for adsorption is larger and adsorption curve increases more rapidly in low-pressure section shown in Figure 6(a). Focusing on the value of $B$ in shale adsorption isotherm and the shape of adsorption isotherm curve, we figure out that the curve becomes gradually convex as the value of $B$ increases, as shown in Figure 6(b). This illustrates that the generated shale adsorption isotherm can express the difference of heat of adsorption released between different shale samples. Furthermore, the changes in the shape of the curve are relevant to changes in heat of adsorption.

\section{Conclusion}

(1) The new shale adsorption isotherm is built up based on Langmuir adsorption isotherm, BET isotherm, and Freundlich isotherm, which can offer description for shale adsorption isotherm including monolayer adsorption, multilayer adsorption, and capillary condensation processes. The new shale adsorption isotherm can be converted to Langmuir, BET, and Freundlich isotherms by giving certain values to variables.

(2) The variables in new shale adsorption isotherm are related to coefficients and exponents in Langmuir, BET, and Freundlich adsorption isotherms. The physical and chemical meanings of parameters are figured out and ranges for each parameter are determined, which is used to restrict value of variables in the adsorption isotherm when doing regression analysis to match data from shale samples adsorption experiment.

(3) Based on new shale adsorption isotherm and variable range, curve fitting of relative pressure versus amount of adsorption has been performed. The adsorption isotherms with ability to illustrate the process of monolayer adsorption, multilayer adsorption, and capillary condensation for 80 shale samples from Ordos Basin and Sichuan Basin are obtained. The results of curve fitting are highly accurate.

(4) Variable $B$ in shale adsorption isotherm is related to shape of adsorption curve due to adsorption heat. Variables in shale adsorption isotherm are related to shape of adsorption curve and parameter of heat of adsorption. Adsorption isotherm curve becomes gradually convex as the value of $B$ 


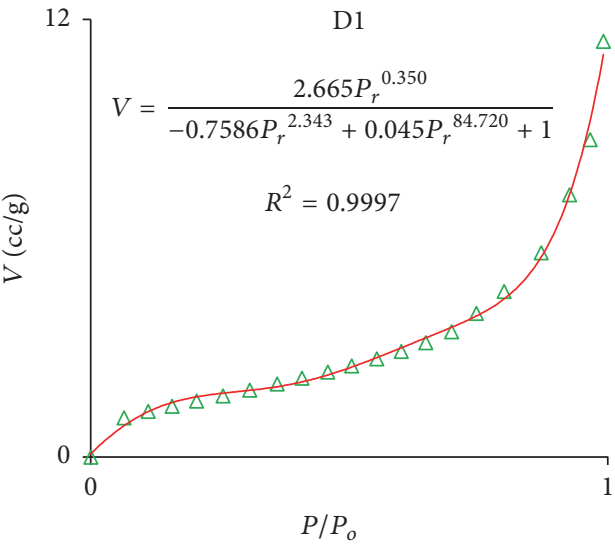

$\triangle \quad$ Data

— Fitting curve

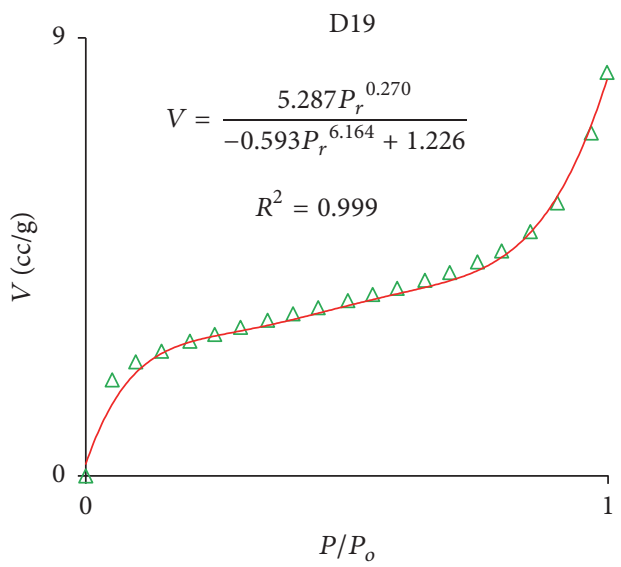

$\triangle \quad$ Data

— Fitting curve

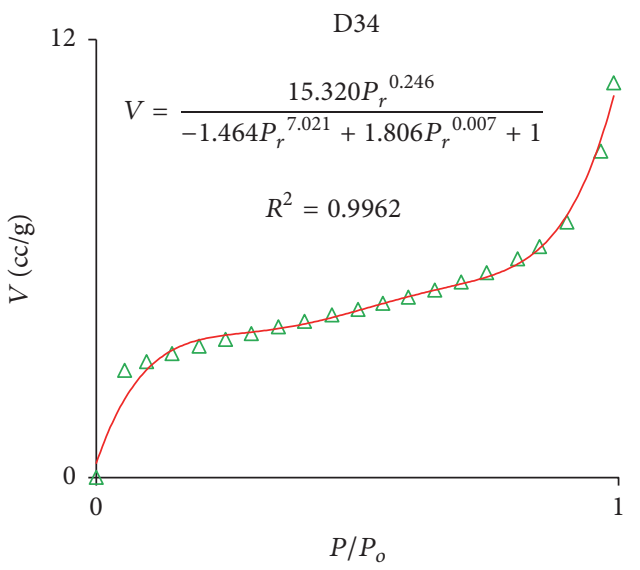

$\triangle \quad$ Data

- Fitting curve

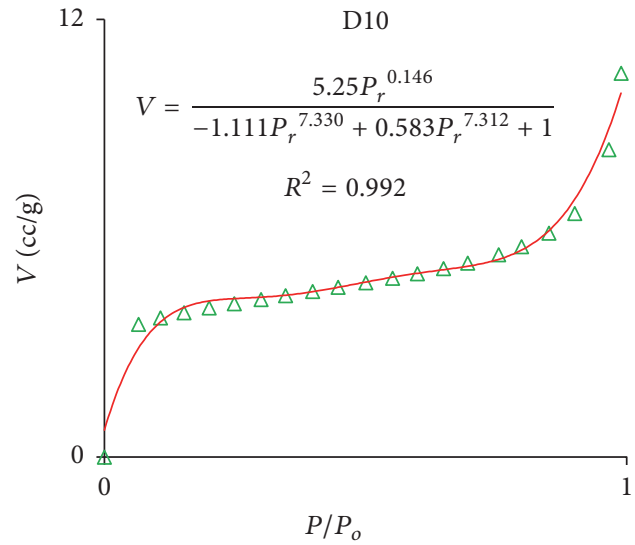

$\triangle \quad$ Data

— Fitting curve

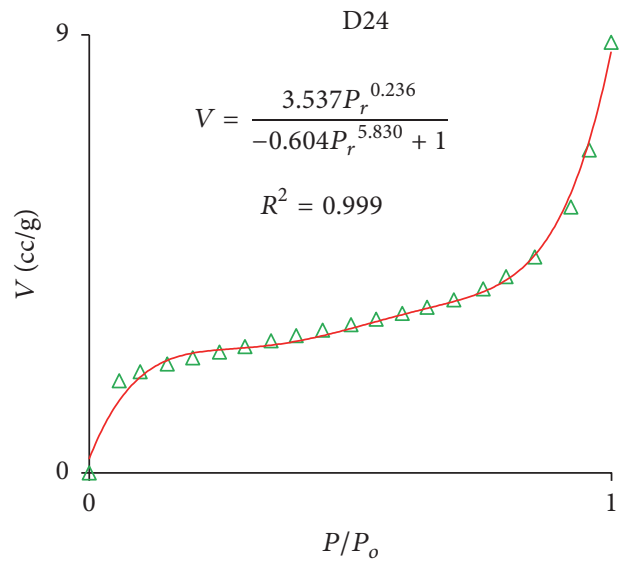

$\triangle$ Data

— Fitting curve

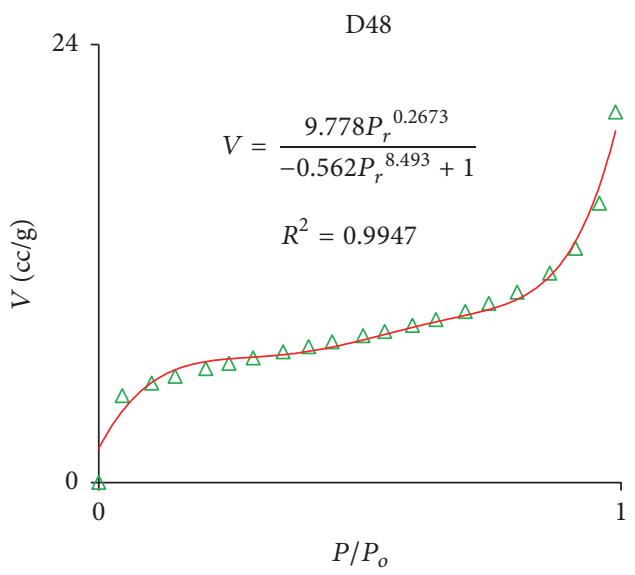

$\triangle$ Data

- Fitting curve

Figure 5: Curve fitting for adsorption isotherm. 


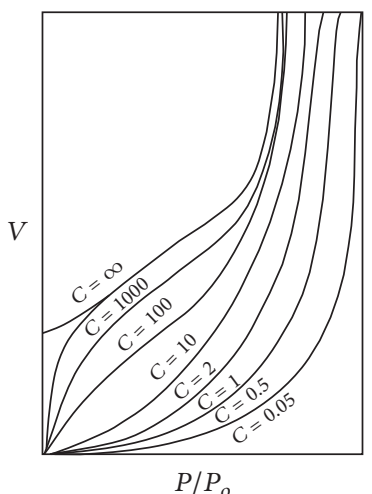

(a)

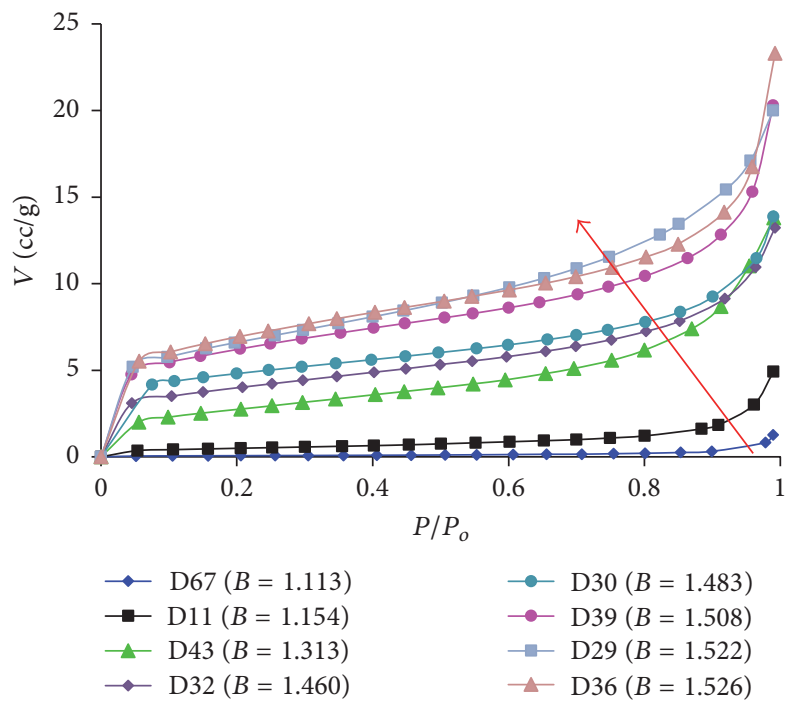

(b)

FIGURE 6: Change in shape of adsorption curve versus change in value of $B$.

increases. Computation according to physical and chemical meaning of coefficient $B$ on heat of adsorption between adsorbate at first layer and adsorbent demonstrates that diversity exists among the heat of adsorption from different shale samples.

\section{Nomenclature}

$V: \quad$ Adsorption volume $(\mathrm{cc} / \mathrm{g})$

$P: \quad$ Equilibrium pressure (MPa)

$V_{m}: \quad$ Saturated adsorption volume (cc/g)

$b: \quad$ Coefficient

$P_{o}: \quad$ Saturated vapor pressure at certain temperature $(\mathrm{MPa})$

$c: \quad$ Coefficient

$m: \quad$ Adsorption mass (g/g)

$k$ : $\quad$ Coefficient

$n: \quad$ Coefficient (Mpa)

$P r: \quad$ The ration of equilibrium pressure $P$ and saturated vapor pressure $P_{0}(1)$

$\Delta H_{m}$ : Adsorption enthalpy (J)

$R: \quad$ Molar gas constant $(\mathrm{J} /(\mathrm{mol} \cdot \mathrm{K}))$

$T: \quad$ Temperature (K)

$\rho_{g}: \quad$ Gas density $(\mathrm{g} / \mathrm{ml})$

$A$ : Variable

B: $\quad$ Variable

M: Variable

$N$ : Variable

$K$ : Variable

$a_{1}:$ Constant

$b_{1}$ : Constant

g: Constant

$E_{1}$ : Heat of adsorption between adsorbate at first layer and adsorbent $(\mathrm{kJ} / \mathrm{mol})$

$E_{L}: \quad$ Heat of adsorption between adsorbate at $n$ layer and adsorbate at $n+1$ layer $(n \geq 1)$ $(\mathrm{kJ} / \mathrm{mol})$.

\section{Conflicts of Interest}

The authors declare that they have no conflicts of interest.

\section{Acknowledgments}

The experimental data support provided by State Key Laboratory of Oil and Gas Reservoir Geology and Exploration is gratefully acknowledged. The authors also thank Dr. Christine Ehlig-Economides from University of Houston for her guidance and assistance.

\section{References}

[1] D. J. K. Ross and R. M. Bustin, "Characterizing the shale gas resource potential of Devonian-Mississippian strata in the Western Canada sedimentary basin: application of an integrated formation evaluation," AAPG Bulletin, vol. 92, no. 1, pp. 87-125, 2008.

[2] S. Chen, Y. Zhu, H. Wang, H. Liu, W. Wei, and J. Fang, "Shale gas reservoir characterisation: a typical case in the southern Sichuan Basin of China," Energy, vol. 36, no. 11, pp. 6609-6616, 2011.

[3] F. Yang, Z. Ning, R. Zhang, H. Zhao, and B. M. Krooss, "Investigations on the methane sorption capacity of marine shales from Sichuan Basin, China," International Journal of Coal Geology, vol. 146, pp. 104-117, 2015.

[4] S. R. Etminan, F. Javadpour, B. B. Maini, and Z. Chen, "Measurement of gas storage processes in shale and of the molecular diffusion coefficient in kerogen," International Journal of Coal Geology, vol. 123, pp. 10-19, 2014.

[5] M. A. Ahmadi and S. R. Shadizadeh, "Experimental investigation of a natural surfactant adsorption on shale-sandstone reservoir rocks: Static and dynamic conditions," Fuel, vol. 159, article no. 9338, pp. 15-26, 2015.

[6] F. Xiong, X. Wang, M. A. Amooie, M. R. Soltanian, Z. Jiang, and J. Moortgat, "The shale gas sorption capacity of transitional 
shales in the Ordos Basin, NW China," Fuel, vol. 208, pp. 236246, 2017.

[7] R. Sakurovs, S. Day, S. Weir, and G. Duffy, "Application of a modified Dubinin - Radushkevich equation to adsorption of gases by coals under supercritical conditions," Energy \& Fuels, vol. 21, no. 2, pp. 992-997, 2007.

[8] T. F. T. Rexer, M. J. Benham, A. C. Aplin, and K. M. Thomas, "Methane adsorption on shale under simulated geological temperature and pressure conditions," Energy \& Fuels, vol. 27, no. 6, pp. 3099-3109, 2013.

[9] R. Heller and M. Zoback, "Adsorption of methane and carbon dioxide on gas shale and pure mineral samples," Journal of Unconventional Oil and Gas Resources, vol. 8, pp. 14-24, 2014.

[10] Y. Dang, L. Zhao, X. Lu et al., "Molecular simulation of $\mathrm{CO}_{2} / \mathrm{CH}_{4}$ adsorption in brown coal: Effect of oxygen-, nitrogen-, and sulfur-containing functional groups," Applied Surface Science, vol. 423, pp. 33-42, 2017.

[11] K. Jessen, G.-Q. Tang, and A. R. Kovscek, "Laboratory and simulation investigation of enhanced coalbed methane recovery by gas injection," Transport in Porous Media, vol. 73, no. 2, pp. 141-159, 2008.

[12] I. Langmuir, "The constitution and fundamental properties of solids and liquids, Part I: solids," Journal of the American Chemical Society, vol. 38, no. 11, pp. 2221-2295, 1916.

[13] I. Langmuir, "The constitution and fundamental properties of solids and liquids. II. Liquids.1," Journal of the American Chemical Society, vol. 39, no. 9, pp. 1848-1906, 1917.

[14] E. C. Markham and A. F. Benton, "The adsorption of gas mixtures by silica," Journal of the American Chemical Society, vol. 53, no. 2, pp. 497-507, 1931.

[15] J. A. V. Butler and C. Ockrent, "Studies in electrocapillarity. III," The Journal of Physical Chemistry, vol. 34, no. 12, pp. 2841-2859, 1930.

[16] Á. Piñeiro, P. Brocos, A. Amigo, J. Gracia-Fadrique, and M. G. Lemus, "Extended Langmuir isotherm for binary liquid mixtures," Langmuir, vol. 17, no. 14, pp. 4261-4266, 2001.

[17] E. Besedovß, D. Bobok, and E. Besedová, "Single-component and binary adsorption equilibrium of 1,2 dichloroethane and 1,2 dichloropropane on activated carbon," Petroleum \& Coal, vol. 47, no. 2, pp. 47-54, 2005.

[18] J. S. Jain and V. L. Snoeyink, "Adsorption from bisolute systems on active carbon," Journal of the Water Pollution Control Federation, vol. 45, no. 12, pp. 2463-2479, 1973.

[19] Y. S. Ho and G. McKay, "Correlative biosorption equilibria model for a binary batch system," Chemical Engineering Science, vol. 55 , no. 4 , pp. 817-825, 2000.

[20] J. Toth, "State equation of the solid-gas interface layers," Acta Chimica Academiae Scientiarum Hungaricae, vol. 69, pp. 311328, 1971.

[21] A. P. Terzyk, J. Chatłas, P. A. Gauden, G. Rychlicki, and P. Kowalczyk, "Developing the solution analogue of the Toth adsorption isotherm equation," Journal of Colloid and Interface Science, vol. 266, no. 2, pp. 473-476, 2003.

[22] M. Jaroniec and J. Töth, "Adsorption of gas mixtures on heterogeneous solid surfaces: I. Extension of Tóth isotherm on adsorption from gas mixtures," Colloid and Polymer Science, vol. 254, no. 7, pp. 643-649, 1976.

[23] D. M. Ruthven, Principles of adsorption and adsorption processes, John Wiley \& Sons, 1984.

[24] C. Yao, "Extended and improved Langmuir equation for correlating adsorption equilibrium data," Separation and Purification Technology, vol. 19, no. 3, pp. 237-242, 2000.
[25] S. Brunauer, P. H. Emmett, and E. Teller, "Adsorption of gases in multimolecular layers," Journal of the American Chemical Society, vol. 60, no. 2, pp. 309-319, 1938.

[26] G. Wang, K. Wang, and T. Ren, "Improved analytic methods for coal surface area and pore size distribution determination using $77 \mathrm{~K}$ nitrogen adsorption experiment," International Journal of Mining Science and Technology, vol. 24, no. 3, pp. 329-334, 2014.

[27] G. L. Aranovich and M. D. Donohue, "A New Approach to Analysis of Multilayer Adsorption," Journal of Colloid and Interface Science, vol. 173, no. 2, pp. 515-520, 1995.

[28] T. L. Hill, “Theory of multimolecular adsorption from a mixture of gases," The Journal of Chemical Physics, vol. 14, no. 4, pp. 268$275,1946$.

[29] B. W. Bussey, "Multicomponent gas adsorption of ideal mixtures," Industrial \& Engineering Chemistry Fundamentals, vol. 5, no. 1, pp. 103-106, 1966.

[30] G. Tiren, "The comparison of different BET-type mixed adsorption equations with some experimental results," Journal of Chemical Industry and Engineering (China), vol. 1, pp. 80-84, 1984.

[31] G. Tiren, "The extended BET adsortion theory in mixture solution," CHemistry, vol. 9, pp. 1-7, 1984.

[32] M. Polanyi, "The potential theory of adsorption," Science, vol. 141, no. 3585, pp. 1010-1013, 1963.

[33] M. M. Dubinin and L. Radushkevich, "Equation of the characteristic curve of activated charcoal," Proceedings of the Academy of Sciences USSR, vol. 55, no. 2, pp. 331-333, 1947.

[34] G. L. Aranovich and M. D. Donohue, "Adsorption isotherms for microporous adsorbents," Carbon, vol. 33, no. 10, pp. 1369-1375, 1995.

[35] N. D. Hutson and R. T. Yang, "Theoretical basis for the Dubinin-Radushkevitch (D-R) adsorption isotherm equation," Adsorption, vol. 3, no. 3, pp. 189-195, 1997.

[36] M. M. Dubinin and V. A. Astakhov, "Description of Adsorption Equilibria of Vapors on Zeolites over Wide Ranges of Temperature and Pressure," in Molecular Sieve Zeolites-II, vol. 102 of Advances in Chemistry, pp. 69-85, ACS Publications, 1971.

[37] W. F. L. Brown, "The joule-thermal effect and the equation of state of gases with non-polar molecules," Russian Journal of Physical Chemistry, vol. 30, pp. 691-704, 1959.

[38] J. Cortés and P. Araya, “The Dubinin-Radushkevich-Kaganer equation," Journal of the Chemical Society, Faraday Transactions 1: Physical Chemistry in Condensed Phases, vol. 82, no. 8, pp. 2473-2479, 1986.

[39] D. Avnir and M. Jaroniec, "An isotherm equation for adsorption on fractal surfaces of heterogeneous porous materials," Langmuir, vol. 5, no. 6, pp. 1431-1433, 1989.

[40] R. Sips, "On the structure of a catalyst surface," The Journal of Chemical Physics, vol. 16, no. 5, pp. 490-495, 1948.

[41] C. R. Clarkson, R. M. Bustin, and J. H. Levy, "Application of the mono/multilayer and adsorption potential theories to coal methane adsorption isotherms at elevated temperature and pressure," Carbon, vol. 35, no. 12, pp. 1689-1705, 1997.

[42] O. Redlich and D. L. Peterson, "A useful adsorption isotherm," The Journal of Physical Chemistry C, vol. 63, no. 6, p. 1024, 1959.

[43] K. Y. Foo and B. H. Hameed, "Insights into the modeling of adsorption isotherm systems," Chemical Engineering Journal, vol. 156, no. 1, pp. 2-10, 2010.

[44] K. A. Bowker, "Barnett Shale gas production, fort worth basin: issues and discussion," AAPG Bulletin, vol. 91, no. 4, pp. 523$533,2007$. 
[45] L. Hong et al., "Experimental study of mineral composition and brittle characteristics in longmaxi formation of lower silurian, southeast chongqing," Science Technology and Engineering, vol. 13, pp. 8567-8571, 2013.

[46] R. M. Pollastro, D. M. Jarvie, R. J. Hill, and C. W. Adams, "Geologic framework of the Mississippian Barnett Shale, BarnettPaleozoic total petroleum system, Bend arch-Fort Worth Basin, Texas," AAPG Bulletin, vol. 91, no. 4, pp. 405-436, 2007.

[47] D. M. Jarvie, R. J. Hill, T. E. Ruble, and R. M. Pollastro, "Unconventional shale-gas systems: the Mississippian Barnett Shale of north-central Texas as one model for thermogenic shale-gas assessment," AAPG Bulletin, vol. 91, no. 4, pp. 475499, 2007.

[48] S. L. Montgomery, D. M. Jarvie, K. A. Bowker, and R. M. Pollastro, "Mississippian Barnett Shale, Fort Worth basin, north-central Texas: gas-shale play with multi-trillion cubic foot potential," AAPG Bulletin, vol. 89, no. 2, pp. 155-175, 2005.

[49] T. Guo, "Evaluation of highly thermally mature shale-gas reservoirs in complex structural parts of the Sichuan Basin," Journal of Earth Science, vol. 24, no. 6, pp. 863-873, 2013.

[50] S. Brunauer, L. S. Deming, W. E. Deming, and E. Teller, "On a theory of the van der Waals adsorption of gases," Journal of the American Chemical Society, vol. 62, no. 7, pp. 1723-1732, 1940.

[51] U. Kuila and M. Prasad, "Specific surface area and pore-size distribution in clays and shales," Geophysical Prospecting, vol. 61, no. 2, pp. 341-362, 2013.

[52] J. C. Groen, L. A. A. Peffer, and J. Pérez-Ramírez, "Pore size determination in modified micro- and mesoporous materials. Pitfalls and limitations in gas adsorption data analysis," Microporous and Mesoporous Materials, vol. 60, no. 1-3, pp. 1-17, 2003.

[53] T. Li, H. Tian, J. Chen, and L. Cheng, "Application of low pressure gas adsorption to the characterization of pore size distribution of shales: An example from Southeastern Chongqing area, China," Journal of Natural Gas Geoscience, vol. 1, no. 3, pp. 221-230, 2016.

[54] S.-B. Chen, Y.-M. Zhu, H.-Y. Wang, H.-L. Liu, W. Wei, and J.-H. Fang, "Structure characteristics and accumulation significance of nanopores in Longmaxi shale gas reservoir in the southern Sichuan Basin," Journal of the China Coal Society, vol. 37, no. 3 , pp. 438-444, 2012.

[55] S. Kondou, T. Ishikawa, and I. Abe, "Adsorption Science (Chinese version)," pp. 37-39, Chemical Industry Press, Beijing, China, 2006.

[56] H. Freundlich, "Over the adsorption in solution," The Journal of Physical Chemistry, vol. 57, Article ID 385471, pp. 1100-1107, 1906.

[57] S. Kondou, T. Ishikawa, and I. Abe, Adsorption Science (Chinese version), p. 36, Chemical Industry Press, Beijing, China, 2006.

[58] S. Duan, M. Gu, X. Du, and X. Xian, "Adsorption Equilibrium of CO2 and CH4 and Their Mixture on Sichuan Basin Shale," Energy \& Fuels, vol. 30, no. 3, pp. 2248-2256, 2016.

[59] S. Kondou, T. Ishikawa, and I. Abe, Adsorption Science (Chinese version), p. 42, Chemical Industry Press, Beijing, China, 2006.

[60] M. D. LeVan and T. Vermeulen, "Binary Langmuir and Freundlich isotherms for ideal adsorbed solutions," The Journal of Physical Chemistry, vol. 85, no. 22, pp. 3247-3250, 1981.

[61] S. Kondou, T. Ishikawa, and I. Abe, Adsorption Science (Chinese version), p. 44, Chemical Industry Press, Beijing, China, 2006. 

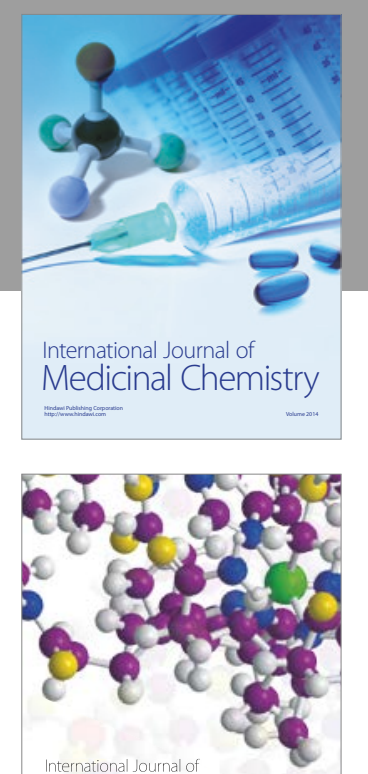

Carbohydrate Chemistry

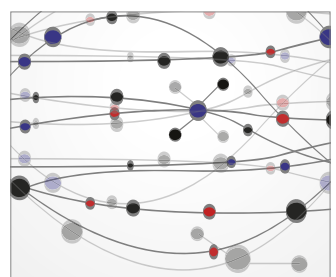

The Scientific World Journal
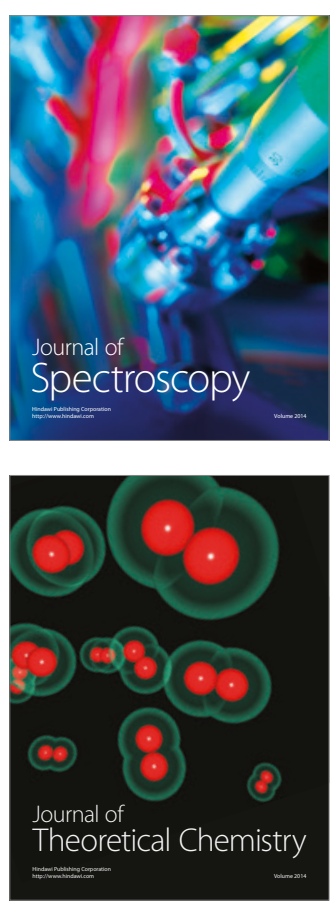
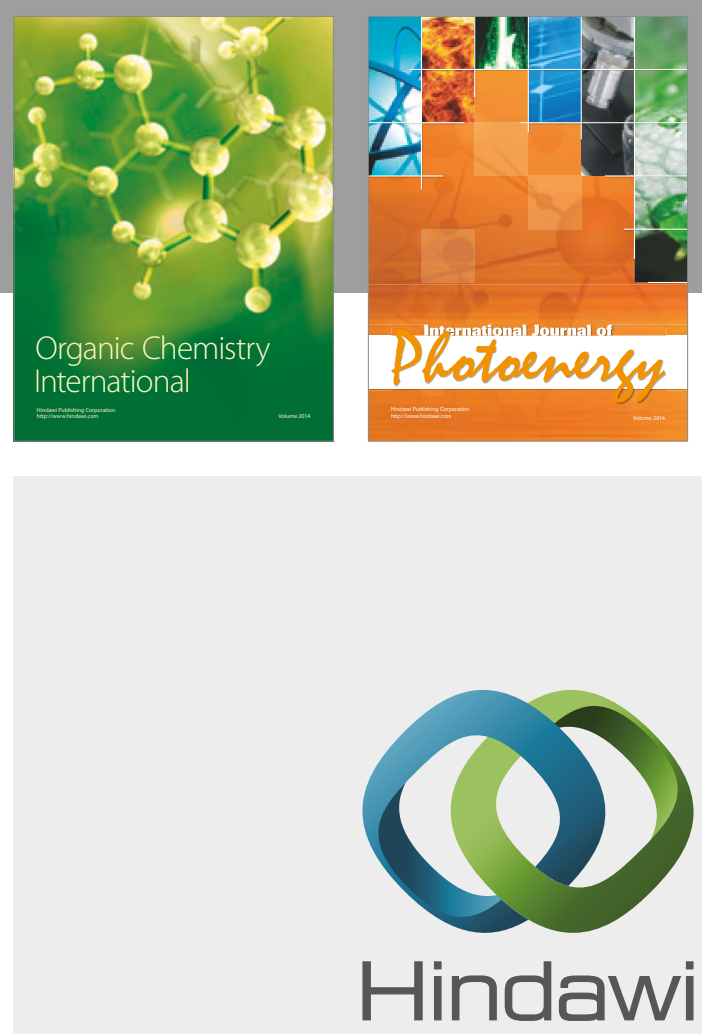

Submit your manuscripts at

https://www.hindawi.com

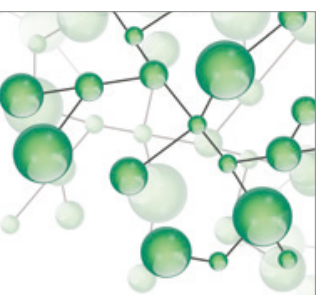

International Journal of

Inorganic Chemistry

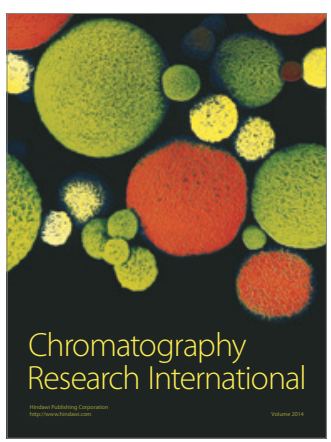

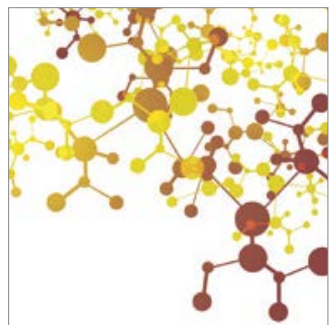

Applied Chemistry
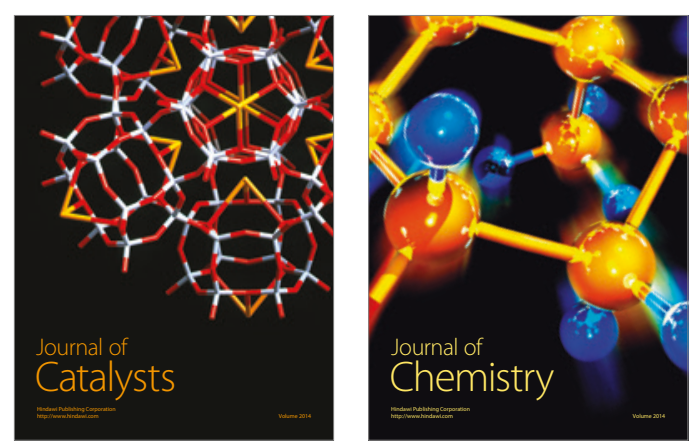
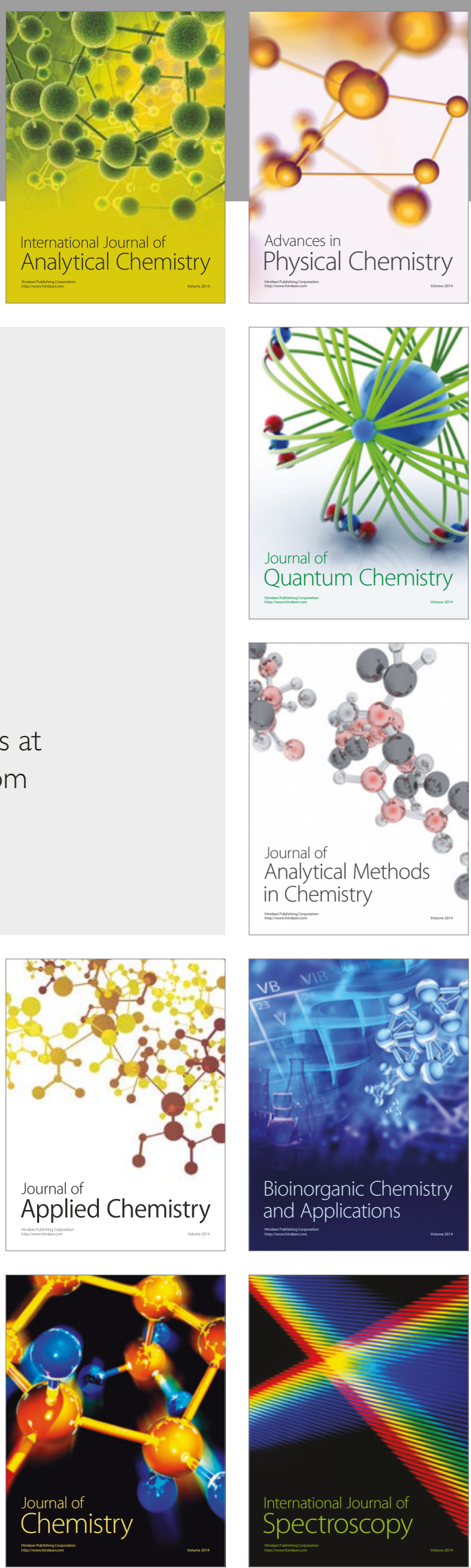